\title{
A experiência do teatro: de John Dewey ao espectador do teatro contemporâneo ${ }^{1}$
}

Leonel Martins Carneiro²

\section{Resumo}

Este trabalho discute a experiência do espectador de teatro. Tal reflexão é embasada na construção histórica do conceito de experiência, que passa a ser aplicado à fruição da arte a partir da década de 1930, por John Dewey. Na esteira das ideias de Dewey, faz-se uma breve reflexão sobre o uso do conceito de experiência na teoria e sobre as vivências práticas do espectador contemporâneo.

Palavras-chave: Arte; Espectador; Experiência; Teatralidade; Teatro da Vertigem.

\begin{abstract}
This paper aims to discuss the experience of the spectator of theater. Such reflection is based on the historical construction of the concept of experience, which in the 30's started to be applied in the field of the arts by John Dewey. Following Dewey's ideas, we made a brief reflection about the employment of the concept of experience in theory and practice of the contemporary spectator.
\end{abstract}

Keywords: Experience; Spectator; Societas Raffaello Sanzio; Theatricality; Teatro da Vertigem.

Dentre as diversas manifestações de teatralidade que espectadores do século XXI têm acesso, é crescente o número das que se encaixam na classificação "teatro contemporâneo." Olhando para tais obras parece impossível dizer que elas apresentam uma característica comum e generalizada. Porém, é comum a elas, em sua multiplicidade, um certo tipo de função conferida ao espectador que deve completar os espaços deixados pela obra na construção de sentido da cena. Se o teatro foi por muito tempo classificado por sua dramaturgia e durante o século XX pôde ser classificado também pelas opções do encenador e do ator, o teatro do século XXI, ao que parece, passa a ser fundamentalmente diferenciado pela relação entre a obra o seu espectador.

Alguns conceitos parecem chave para uma abordagem teórica desta cena contemporânea, dentre os quais se podem destacar: teatralidade, realidade e expe-

\footnotetext{
1 Este artigo é uma síntese dos primeiros resultados da pesquisa Teatralidade e experiência, desenvolvida pelo autor no Programa de Pós-Graduação de Artes Cênicas da Universidade de São Paulo e fomentada pela FAPESP.

2 Doutorando no Programa de Pós-Graduação em Artes Cênicas da Universidade de São Paulo, no qual defendeu sua dissertação de mestrado em 2011 é graduado em artes cênicas pela Universidade Estadual de Campinas. Trabalha como Ator, pesquisador, professor e editor das Revistas Sala Preta e aSPAs. Contato: leonelmcarneiro@gmail.com
} 
riência. Dentre estes três conceitos, o presente artigo se concentra no conceito de experiência, por entendê-lo como base para a discussão dos outros dois, uma vez que as noções de teatralidade e realidade são construídas a partir das experiências individuais e coletivas. Esta opção também é motivada pela escassez de trabalhos que tratem deste conceito no âmbito do teatro.

O termo experiência, derivado do latim experientia, sempre foi utilizado em seu sentido mais amplo para designar um tipo de conhecimento adquirido por uma prática, um estudo, uma observação. É necessário, no entanto, diferenciar a experiência em seu sentido mais geral da experiência em seu sentido mais técnico, que também pode ser chamado de experimentação. Enquanto no primeiro caso a palavra é utilizada de forma mais ampla e engloba todas as experiências cotidianas, das menos às mais significativas, no segundo refere-se a algo que pode ser testado de forma a comprovar uma hipótese, ou seja, pode ser considerado um sinônimo de experimento (científico).

No campo da teoria do teatro, em especial daquela relacionada ao teatro contemporâneo, a palavra experiência é largamente utilizada. Há desde os experimentos cênicos até as mais diversas experiências do espectador. Há propostas que encaram a arte contemporânea como nova e única na história devido o seu caráter relacional (BOURRIAUD, 2009) e outras que se focam em como a arte propicia, também de forma inovadora, experiências de choque para o espectador (FÉRAL, 2012). Mas nesse contexto de "novidades" trazidas pela arte contemporânea, o tema da experiência do espectador tem uma trajetória que merece ser revista e que pode revelar a escuridão que se adentra ao ignorar a história.

Antes de utilizar, mais uma vez, a palavra experiência, gasta pelo uso excessivo e generalizante, procura-se fazer uma breve reflexão sobre a história de seu uso aplicado ao campo das artes. Deve-se, portanto, atribuir os créditos a quem primeiro trouxe o uso da palavra experiência para o campo da recepção da arte: o filósofo e psicólogo americano John Dewey.

\section{Dewey e a arte como experiência}

A obra de Dewey é vasta e plural, e influenciou de forma definitiva o pensamento contemporâneo. Muito ativo, o professor americano dedicou a maior parte dos seus 92 anos de vida à docência. A partir de um ciclo de palestras sobre a "filosofia da arte", feitas a convite do Departamento de Filosofia da Universidade Harvard, que nasce o 
livro Arte como experiência, o primeiro a tratar da experiência da recepção da arte. 0 livro conserva muito da característica de um texto feito para uma palestra, possuindo numerosos exemplos e retomadas dos assuntos. A obra é composta de forma espiral e ascensional, o que pode ser visto como um diálogo entre a forma e o assunto abordado. Através de acumulações, o filósofo atribui significados para a palavra experiência e os distingue.

Para Dewey, no sentido mais amplo do termo, "experiência é um resultado da interação entre uma criatura viva e algum aspecto do mundo em que ela vive" (2010, p.122). A acepção e abordagem que ele dá ao termo estão claramente ligadas a uma corrente filosófica que tem como fundador Aristóteles, que considerava, diferentemente de Platão, que só há um mundo e que o único modo de conhecê-lo é se concentrar sobre sua concretude.

A Metafísica de Aristóteles traz, pela primeira vez, a relação entre arte, ciência, memória, sensação e experiência. Para o filósofo grego, existem cinco níveis de conhecimento que são progressivos. O primeiro e mais superficial deles é a sensação, a partir da qual emerge a memória. Um ser vivo que tem memória será melhor do que aquele que não tem, pois o primeiro é capaz de aprender. Entrelaçada à memória está a experiência. O que diferencia o homem dos outros animais é justamente a capacidade de desenvolver os conhecimentos da arte e da ciência a partir de suas experiências.

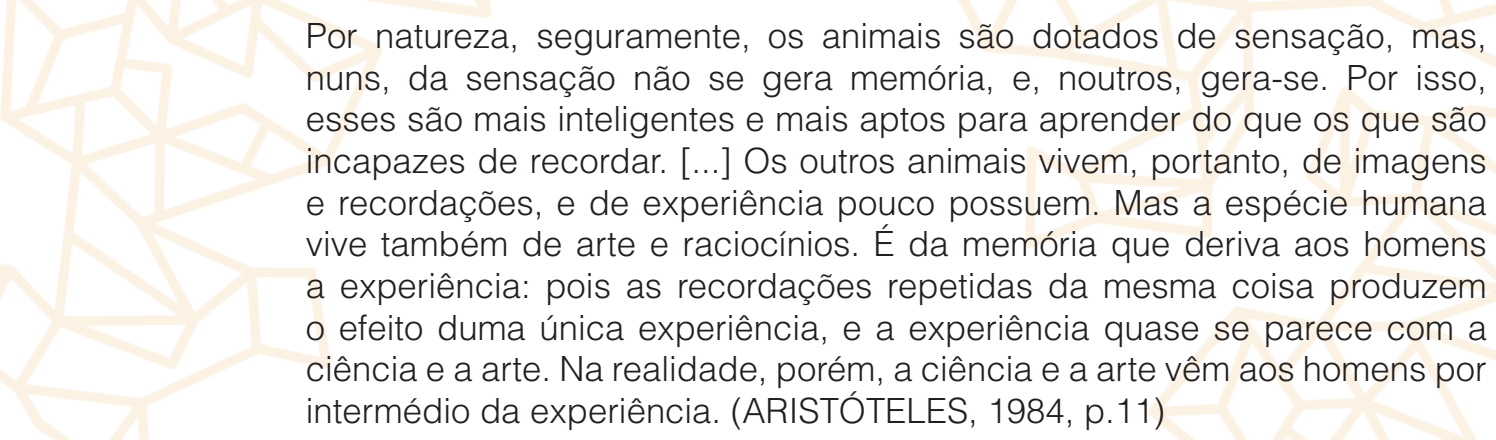

Memória e experiência podem ter uma função biológica de aprendizagem para os animais, mas para o homem elas são muito mais que isso. A experiência humana é capaz de gerar a arte e a ciência e através destas exprime a possibilidade de síntese de múltiplos aspectos do mundo, que retroalimentam sua vivência.

A experiência é comum à todos os animais e faz parte de um sistema que os permite adaptar-se ao meio ou o meio às suas necessidades. Seguindo esta mesma linha de raciocínio fundada por Aristóteles está a concepção de Charles Darwin que também exerceu grande influência sobre o pensamento moderno, em especial sobre 
a psicologia. Se por um lado, de forma ampla, pode-se dizer que a experiência é o principal mecanismo da evolução segundo a teoria das espécies de Darwin, por outro, como nos aponta Kaplan (apud DEWEY, 2010 p.23) "com base nos princípios darwinianos, Dewey tinha a convicção de que a mente não podia ser uma espectadora desinteressada dos acontecimentos, estando, antes, ativamente envolvida neles."

Há também na obra do filósofo americano a influência do pensamento de um dos fundadores da psicologia e da psicanálise, Sigmund Freud, bem como dos preceitos de Willian James. Se por um lado existe uma relação implícita em seu texto entre a experiência e o princípio de prazer $^{3}$ de Freud, por outro, a ideia de James sobre a relação entre tempo e experiência é central para sua tese.

Como disse James, aprendemos a patinar no verão, depois de haver começado no inverno. O tempo, como organização da mudança, é crescimento, e o crescimento significa que uma série variada de mudanças entra nos intervalos de pausa e repouso, de conclusões que se tornam os pontos iniciais de novos processos de desenvolvimento. (DEWEY, 2010, p.90)

Além dos escritos do próprio James, fundamentam também a sua abordagem da experiência a concepção das funções superiores da mente que foram aplicadas às artes (mais especificamente ao cinema) em 1915-1916 pelo professor de Harvard, Hugo Münsterberg. Conforme nos aponta Joe Burnett em sua introdução do livro The middle Works of John Dewey (2008), os pesquisadores eram muito próximos no fim do século XIX, o que rendeu inclusive elogios de Dewey à Münsterberg, mas depois eles se afastaram por divergências de pensamento. De qualquer forma, os conceitos de atenção, memória, imaginação e emoção, que estavam na pauta das principais pesquisas na área da psicologia, são explorados por Münsterberg (2004) em sua relação com a recepção do espectador. ${ }^{4}$

Segundo Münsterberg, “a cena que mantém vivo nosso interesse [no cinema] certamente envolve muito mais do que as simples impressões visuais de movimento e profundidade. Nós temos que acompanhar a cena com uma riqueza de ideias". (2004, p.31 $)^{5}$ Esta riqueza de ideias, a qual o psicólogo alemão se refere, está diretamente

3 Em seu ensaio Além do princípio do prazer (2006), Freud relata a existência de mecanismos psíquicos que fazem uma pré-seleção das experiências que se tornam conscientes e salienta a dificuldade de se entender os mecanismos de processamento da vivência de um choque, como, por exemplo, a experiência de risco de morte de quem sobrevive a um acidente de trem.

4 Para mais detalhes sobre a teoria da recepção desenvolvida por Hugo Münsterberg, consultar a dissertação de mestrado $A$ atenção e a cena (CARNEIRO, 2011).

5 "The scene which keeps our interest alive certainly involves much more than the simple impression of moving and distant objects. We must accompany those sights with a wealth of ideas." 
relacionada às memórias e experiências acumuladas pelo indivíduo durante sua vida. É justamente no encontro entre o produto artístico, a experiência e a memória do espectador que é produzido o sentido da obra.

No contexto efervescente de ideias do início do século $\mathrm{XX}$, pouco tempo depois da publicação do livro de Dewey (que data de 1934) sobre a arte como experiência, surge o ensaio $O$ narrador de Walter Benjamin (publicado em 1936), que fala sobre e da experiência humana e a sua narração. Para Benjamin, a impossibilidade da narrativa na modernidade e o declínio da experiência são indissociáveis. Em seu $O$ narrador, o filósofo aponta que a experiência torna-se impossível na modernidade e divide a experiência em dois tipos:

O nosso crítico [Benjamin] distinguia entre duas modalidades de conhecimento, indicadas por duas palavras diversas em alemão: Erfahrung e Erlebnis.

Erfahrun' é o conhecimento obtido através de uma experiência que se acumula, que se prolonga, que se desdobra, como numa viagem (e viajar, em alemão, é fahren); o sujeito integrado numa comunidade dispõe de critérios que lhe permitem ir sedimentando as coisas, com o tempo. Erlebnis é a vivência do indivíduo privado, isolado; é a impressão forte, que precisa ser assimilada às pressas, que produz efeitos imediatos. (KONDER, 1999, p. 83)

Diante da divisão da experiência feita por Benjamin, vale ressaltar que ainda que Dewey tenha algumas categorias de experiência, é fundamental para ele a noção de continuidade entre elas, não havendo uma experiência social separada se uma individual. A experiência comum e a estética são também partes de um mesmo corpo para o filósofo americano, feitas de uma mesma matéria. Esta visão holística que permeia a teoria deweyana acaba por distanciá-la contundentemente dos escritos de Walter Benjamin. De fato, o ponto no qual as teorias de Benjamin e Dewey mais se aproximam é no que se refere à superficialidade da experiência moderna.

\footnotetext{
O gosto pelo fazer, a ânsia de ação, deixa muitas pessoas, sobretudo no meio humano apressado e impaciente que vivemos, com experiências de uma pobreza quase inacreditável, todas superficiais. [...] O que é chamado experiência fica tão disperso e misturado que mal chega a merecer este nome. A resistência é tratada como uma obstrução a ser vencida, e não como um convite a reflexão. O indivíduo passa a buscar, mais ainda inconscientemente do que por uma escolha deliberada, situações em que possa fazer o máximo de coisas no prazo mais curto possível. (DEWEY, 2010, p. 123).
}

Em 1934, o professor americano já antevia uma característica que iria se desenvolver até se tornar predominante no século XXI: a ânsia de ação. Este gosto pelo fazer é em grande parte responsável pelo desaparecimento do "espectador tradicional" do teatro contemporâneo, que foi substituído em grande parte dos casos pela figura do "espectador partner". Mesmo diante desta constatação, Dewey em nenhum momento 
diz, como Benjamin, que a experiência é impossível para o homem moderno. Para Dewey, "a experiência ocorre continuamente, porque a interação do ser vivo com as condições ambientais está no próprio processo de viver [...] mas muitas vezes a experiência é incipiente." (2010, p. 109).

Em contraste com a experiência do cotidiano, John Dewey apresenta o que ele chama de uma experiência ${ }^{6}$, situação na qual há um começo, meio e fim e em que ela pode adquirir um sentido marcante para o indivíduo, tornando-se uma experiência significativa.

Desta forma, uma primeira divisão possível da experiência, na obra do filósofo, seria entre a experiência comum (ou cotidiana) e a experiência significativa ${ }^{7}$. A experiência na arte tem um grande potencial para ser de cunho significativo, pois "na arte a experiência é liberada das forças que impedem e confundem seu desenvolvimento" (DEWEY, 2010, p.472). A experiência na (e da) arte tem uma característica que a distingue de uma experiência significativa na vida cotidiana (por exemplo, de um acidente de carro) que está ligada ao seu caráter estético e a sua organização: “A arte é o desenvolvimento esclarecido e intensificado de traços que pertencem a toda experiência normalmente completa" (DEWEY, 2010, p.125). Desta forma, Dewey faz mais uma delimitação da experiência da arte, caracterizando-a como uma experiência estética.

O 'sentido' abarca uma vasta gama de conteúdos: o sensorial, o sensacional, o sensível, o sensato e o sentimental, junto com o sensual. Inclui quase tudo, desde o choque físico e emocional cru até o sentido em si - ou seja, o significado das coisas presentes na experiência imediata. (DEWEY, 2012, p.88)

O significado desta experiência estética se dá, portanto, na fusão entre aquilo que a percepção atenta recebe através dos sentidos e as experiências anteriores. Neste processo de experiência da obra de arte há dois polos, de igual importância, que trocam ativamente, a fim de produzir a experiência: o artístico (a criação da obra empreitada pelo artista) e o estético (campo apreciativo do espectador). De qualquer um dos pontos de vista é importante dizer que a arte "faz algo diferente de conduzir a uma experiência: constitui [em si] uma experiência" (DEWEY, 2010, p.184). Para o filósofo, seria fundamental a existência de um recurso linguístico capaz de unir as ideias do artístico e do estético.

6 A tradutora da versão brasileira opta por traduzir "an experience", na maior parte das vezes, como "experiência singular". No entanto, parece ser mais acertado traduzir literalmente, como "uma experiência" para que não pareça um conceito. Os conceitos, na verdade, estão caracterizados quando ele fala de "experiência estética" ou de "experiência significativa".

7 Apesar desta diferenciação, na operação analítica de Dewey é importante notar que para sua ele há uma continuidade entre estes dois tipos de experiência. 
Na língua inglesa [e na portuguesa também- N.A.] não há uma palavra que inclua de forma inequívoca o que é expresso pelas palavras "artístico" e "estético". Visto que o "artístico" se refere primordialmente ao ato de produção e o "estético", ao de percepção e prazer, a inexistência de um termo que designe o conjunto dos dois processos é lamentável. [...] A concepção da experiência consciente como a percepção de uma relação entre o fazer e o estar sujeito a algo permite compreender a ligação que a arte como produção, por um lado, e a percepção e apreciação como prazer, por outro, mantêm entre si. (DEWEY, 2010, p.125-126)

Tem-se, portanto, dois polos necessários para a caraterização de uma obra de arte, sob o ponto de vista da experiência. O artístico é uma etapa de produção da obra na qual a experiência do artista acontece, mas ela só atinge seu fim quando há o confronto o com o espectador (neste ponto fim e finalidade se confundem). A obra de arte é aquilo que o produto artístico faz na e com a experiência e, portanto, depende do espaço e do sujeito envolvidos. Para que ela exista é necessário que haja uma experiência estética ${ }^{8}$.

Para a compreensão da experiência com começo, meio e fim, postulada por Dewey como uma troca entre o ser e o mundo, inclusive quando se refere à experiência da arte, é importante dizer que ela não é em si fechada, mas "quando se chega a uma conclusão, ela é um movimento de antecipação e acumulação, um movimento que finalmente se conclui"' (DEWEY, 2010, P.113). Portanto, a conclusão da experiência é a consumação de um movimento iniciado com um fato vivido e processado em uma relação dialética com suas vivências anteriores, tendo sua própria qualidade estética. Partindo deste pressuposto é possível dizer que mesmo essa conclusão é provisória, uma vez que a experiência está continuamente em movimento.

A experiência estética, postulada pelo professor americano, está diretamente ligada à ideia de tensão. Há uma troca de energias, uma busca de equilíbrio, que só é encontrado na conclusão da experiência. A conclusão é sempre provisória e o desequilíbrio ocorre novamente, criando um fluxo contínuo. Porém, "é impossível exagerar a afirmação de que aquilo que não é imediato não é estético" (DEWEY, 2010, p. 234). Nem sempre uma experiência gera um desequilíbrio que é resolvido de forma instantânea durante o espetáculo. Esta é, justamente, a brecha aberta por Dewey que permite pensar a experiência no teatro contemporâneo.

8 A ideia de estética de Dewey é muito diversa e precede a de Adorno. Para mais informações sobre a estética de Dewey, recomenda-se a leitura de Richard Shusterman (1998). 


\section{A experiência do teatro contemporâneo}

A busca por compreender a experiência no teatro contemporâneo não é tarefa fácil. Por um lado, a teorização da cena, em especial a partir dos anos de 1980, tem se utilizado, em um sentido amplo e múltiplo, da palavra experiência para caracterizar a relação do espectador com a obra artística. Por outro, o próprio artista (através de sua obra), passou a buscar a vivência da obra pelo espectador, no que ela tem de mais sinestésico.

Diante deste quadro, constata-se que há uma grande diferença entre que o vivemos hoje e o que foi visto e descrito por Dewey nos anos de 1930. Temos mais teorias que abordam a experiência do ponto de vista do espectador e espetáculos que visam uma comunicação não-dramática com este. Se já existia dificuldade em compreender a experiência do espectador dramático ou épico, o problema se aprofunda e se complexifica quando o que está em pauta é a cena contemporânea.

Não é muito fácil, no caso de quem percebe e aprecia, compreender a união
intima do fazer com o sofrer, tal como se dá no criador. Somos levados a
crer que o primeiro simplesmente absorve o que existe sob forma acabada,
sem se dar conta que esta absorção envolve atividades comparáveis às do
criador. Mas receptividade não é passividade. Também ela é um processo
composto por uma série de atos reativos que se acumulam em direção à
realização objetiva (DEWEY, 2010, p.134)

Ainda que se tenha avançado muito na compreensão do espectador como receptor ativo, existe grande dificuldade em compreendê-lo como capaz de realizar e sofrer a ação, simultaneamente, em seu papel de espectador. Há um difícil equilíbrio que deve ser atingido pela obra para que a experiência possa acontecer.

A experiência é limitada por todas as causas que interferem na percepção das relações entre o estar sujeito e o fazer. Pode haver interferência pelo excesso da receptividade daquilo a que se é submetido. O desequilíbrio, em qualquer desses lados embota a percepção das relações e torna a experiência parcial e distorcida, com um significado escasso ou falso. (DEWEY, 2010, p. 123)

Para sondar a experiência do espectador da cena contemporânea, este estudo toma por base os espetáculos dos grupos teatrais Teatro da Vertigem ${ }^{9}$ (Brasil) e

9 O Teatro da Vertigem é uma companhia teatral brasileira fundada em 1991 na cidade de São Paulo e dirigida por Antônio Araújo. Sua atuação tem como destaque a utilização de espaços públicos (site specifics) para a realização de suas peças. Alguns materiais sobre o grupo já foram produzidos como o livro organizado por Sílvia Fernandes Teatro da vertigem: BR-3. (São Paulo: Perspectiva, 2006.) e o Dossiê do espetáculo Bom Retiro 958m publicado na revista Sala Preta 12.2 http://revistas.usp.br/salapreta/issue/view/4704/showToc. Há também o dossiê publicado pela Revista Sala Preta em 2001 sobre o Apocalipse 11.1 (2001) que agora está publicado on-line: http://revistas.usp.br/salapreta/issue/view/4682/showToc 
Societas Raffaello Sanzio ${ }^{10}$ (Itália), por se pensar que, em suas peças, especialmente nas dirigidas, respectivamente, por Antônio Araújo e Romeo Castellucci, há uma relação muito interessante entre a experiência comum e a experiência estética nestes exemplos.

Os espetáculos são relatados ${ }^{11}$ sempre como um evento ímpar na vida do espectador, que extrapola o lugar da prática cultural e inunda a vida. As peças acabam por ressignificar o mundo. Fornecem um outro ponto de vista sobre o espaço urbano. Lançam novos olhares sobre narrativas humanas (sejam elas músicas, pinturas, literatura, etc.). Como propunha Dewey, estas peças tornam o mundo um lugar diferente para se viver. Laura $^{12}$ - eu queria começar dizendo o quanto foi traumática essa peça, tanto que eu até esqueci o nome da peça... que era a da igreja [o Paraíso Perdido, alguém responde] sim, Paraíso Perdido! (Teatro da Vertigem) Eu tinha 12 anos e meus pais foram e me levaram no lugar dessa classe média que consome cultura e minha mãe viu que tinha um problema com a igreja e ela acho que como era anti-igreja era muito legal. Tinha uma intensidade de vida ali [nesta peça] que foi ali que eu decidi fazer teatro. Era tudo muito intenso... tanto que eu não quis ver depois [quando as peças foram reencenadas], porque eu pensei... o que vai mudar.

A relação com a igreja, a relação com o espaço... eu lembro muito das quedas que vocês faziam aquilo repetidamente, os cantos...[...] ali eu descobri: é muito insossa minha vida, eu preciso desta intensidade!

A experiência estética ao articular-se à experiência comum é capaz influenciá-la de tal forma que opera-se uma mudança definitiva na vida do espectador. As lembranças do canto, das quedas, das falas dos atores de um ambiente ficcional se misturam às lembranças "reais" do indivíduo. Nesse sentido, opera-se um trauma, como descreve a própria espectadora. Um choque tão efetivo de sua atenção que ela passa a viver tendo um novo limite para a intensidade que a vida pode ter. Ela passa a buscar por essa intensidade.

10 Grupo teatral italiano fundado em 1981 por Romeo Castellucci, Claudia Castellucci, Chiara Guidi e Paolo Guidi. Há diversos livros e teses sobre a companhia como:

CASTELLUCCI, Romeo. Epopea della polvere, il teatro della Societas Raffaello Sanzio 1992-1999. Milano: Ubulibri, 2001.

CASTELLUCCI, Claudia. Les pèlerins de la matière: théorie et praxis du théâtre, écrits de la Societas Raffaello Sanzio. Besançon: les Solitaires intempestifs, 2001.

; GUIDI, Chiara, et al. The Theatre of Societas Raffaello Sanzio. London/ New York. Routledge, 2007.

11 No ano de 2013 foram entrevistadas 15 pessoas entre 20 e 60 anos, de diversas classes sociais e profissões extremamente variadas. Dentre os entrevistados temos professores, psicólogos, administradores, estudantes, entre outros. As pessoas também são naturais e moram atualmente em lugares muito diversos uns do outros. Também foi realizada uma entrevista coletiva durante a aula Teatros do Real Ministrada pela professora Sílvia Fernandes no PPGAC-USP.

12 Optamos por, neste artigo, preservar a identidade dos entrevistados para não comprometer o processo de coleta que ainda está em andamento, sendo que os nomes reais estão aqui substituídos por outros, fictícios. 
Assim como Laura, o espectador contemporâneo, em especial o que faz parte do meio artístico, parece cada vez mais interessado em buscar por estas experiências significativas, extra cotidianas, quando vai ao teatro. Se o espectador da década de 1990 estava conhecendo, no Brasil, a potência de uma experiência teatral intensa como a proposta pelo Teatro da Vertigem, nos dias atuais ele parece desejar esse tipo de experiência e procurar cada vez mais por ela. Como nos contou Rodrigo, um estudante de produção teatral de Porto Alegre:

\begin{abstract}
Rodrigo - eu tenho cada vez mais procurado ir em peças que eu acho que tenham potencial para serem significativas para mim. Eu prefiro cada vez mais ir em menos peças, mas que sejam mais significativas. Neste Porto Alegre em Cena ${ }^{13}$ eu fui em poucas coisas, mas me deu um negócio, uma sensação de que era para eu vir ver o Castellucci [Sobre o conceito da face do filho de Deus - Societas Raffaello Sanzio] que eu vim para a porta do teatro mais cedo tentar comprar ingresso. Eu não sei nada sobre a peça, mas acho que vai ser uma experiência intensa, especial.
\end{abstract}

A vontade de viver experiências intensas no teatro parece estar relacionada ao tipo de vida que levamos nas grandes cidades ao redor do mundo. A quantidade de estímulos é tão grande e difusa em nosso dia a dia que entramos em um estado de torpor do qual somente um choque, neste caso estético, pode nos acordar. Pode-se ser eletrocutados na cadeira, como a espectadora que solta um grito de horror, em meio ao silêncio de uma plateia imobilizada, durante uma apresentação no $20^{\circ}$ Porto Alegre em Cena de Sobre o conceito da face do filho de Deus (Societas Raffaello Sanzio) no momento em que o pai defeca, pela terceira vez seguida, em cena. 0 espectador pode também sofrer este choque enquanto caminha distraído pelas ruas de São Paulo durante o espetáculo Bom Retiro 958m (Teatro da Vertigem).

\footnotetext{
Aline - Eu fui assistir o Bom Retiro (Teatro da Vertigem) e tinha um cubano, que eu conheci naquela ocasião, que está estudando teatro no Brasil. Em algum momento eu comecei a reparar como é que os espectadores estavam agindo e eu me dei conta que eu e minha amiga corríamos, íamos na frente. A gente sabia onde a cena ia e já nos posicionávamos. Então eu olhei para o menino cubano e vi que ele estava meio perdido, ele não sabia bem como agir, se posicionar e eu comecei a refletir sobre isso [...] diante disso, eu fiquei pensando muito como o Vertigem nos formou como espectadores desse teatro. A gente está treinado para ser este espectador.
}

Se uma parte dos espectadores brasileiros, em especial os paulistanos, se formou de alguma maneira vendo as peças do Teatro da Vertigem e de todos os outros grupos que passaram a atuar no país, em especial após os anos 2000, seguindo por uma mesma linha de relação com o espectador, é verdade que a maior parte da população, 
quando colocada frente a este tipo de proposta, ficaria tão perdido quanto o cubano. É preciso deixar claro que para este tipo de teatro, "estar perdido" não parece ser um problema, uma vez que isso pode ser apenas mais um ingrediente para a assistência de uma peça se tornar uma experiência significativa.

A percepção do espectador diante de propostas (como essas) acaba por, muitas vezes, vivenciar a ação do espetáculo sem conseguir identificar uma consequência, sem produzir um sentido imediato para a vivência. A percepção do espectador, mesmo o mais especializado (e principalmente esse), "flutua" diante do espetáculo. Ele vai da cena para o outro espectador, do outro espectador para a lembrança de uma outra peça, da lembrança de uma outra peça para a mãe, etc. Ocorre algo muito diferente do que identificou Dewey nos anos de 1930.

A ação e a consequência devem estar unidas na percepção. Essa relação é o que confere significado; apreendê-lo é o objetivo de toda compreensão. 0 âmbito e o conteúdo das relações medem o conteúdo significativo de uma experiência. (DEWEY, 2010, p. 122-123)

Na experiência do teatro contemporâneo a ligação entre ação e consequência está cada vez menos definida na percepção do espectador. Há uma distensão da linha que as une que pode se estender através dos anos. A materialidade da cena passa a não ser um mero objeto que significa, mas atua como um índice da memória de cada espectador que passa a fazer links tomando como base as suas vivências anteriores. Dessa forma, uma grande parte do processamento do espetáculo fica delegada a memória implícita. Assim sendo, uma parcela significativa não é processada conscientemente, mas afeta o desempenho do espectador.

\begin{abstract}
Paula - Em 1999 eu tinha 15 anos. Eu não sei como eu comecei a fazer teatro, mas eu sempre fiz teatro e tinha uma inquietação. Eu morava em Taboão da Serra e queria ver teatro (já que eu fazia). Ai eu descobri em 1999 a USP, onde eu assisti $A$ Revolução dos Beatos do Marco Antônio Rodrigues. Foi meu primeiro choque como espectadora...eu pensava "nossa, eles soltam fogos na entrada!". Era um teatro feito na 'tradição do teatro bem executado'. No mesmo mês eu fui assistir o Apocalipse (Teatro da Vertigem), e não podia, porque era para maiores de 18 anos, mas eu fui e com essa cara de pau eu entrei e assisti duas vezes seguidas. E aquilo assim pra mim foi ... uma porrada no estômago de assim... [...] eu vi outras peças depois do Vertigem, mas essa é a que eu guardo muito concretamente... [...] eu estou falando da parte sentimental, mas para mim não tem como sair daquilo fazer "teatrinho".
\end{abstract}

Em sua fala, o espectador, afastado do momento do acontecimento do espetáculo, demonstra que esse ainda existe em sua memória. A experiência do espetáculo continua a produzir efeitos. Em seus dizeres fica claro que após a experiência de assistir uma das encenações do Teatro da Vertigem ou da Socìetas Raffaello Sanzio, muitas 
vezes, as cenas da ficção surgem como flashes e invadem a realidade da vida cotidiana, marcando especialmente os espaços utilizados pelas encenações. Quando Juliana nos conta de sua relação com os lugares onde foram apresentadas as peças do Teatro da Vertigem em Belo Horizonte, fica muito claro esta intrusão da ficção no espaço real.

Juliana-Tinha a igreja que eu nunca tinha entrado [antes do espetáculo Paraíso Perdido] e que eu nunca mais entrei, mas que eu sempre passo por ela e tem a rua da cadeia [onde foi encenado o Apocalipse 11.1]. Como é uma rua que a gente geralmente não vai, então tem essa lembrança. Todas as vezes que eu voltei lá eu sempre lembrava do espetáculo, virou uma referência de onde teve espetáculo da Vertigem. Uma vez um grupo de teatro alugou um galpão na mesma rua e fizeram uma festa. Eu fui com algumas pessoas que também tinham assistido os espetáculo. A lembrança de todo mundo era "aqui foi a rua da cadeia onde o Vertigem se apresentou". Eu acho que a cadeia tinha sido abandonada a pouco tempo, por que eu tinha um amigo que me falou que tinha sido preso lá, há pouco tempo, por algum motivo besta e que tinha ido para esta cadeia, mas antes do espetáculo, porque quando ela foi usada, já estava abandonada... é uma lembrança invertida, né? Ele foi ver o espetáculo e foi super forte para ele porque ele já tinha estado lá.

Por outro lado, parece muito interessante como as peças, especialmente as do Teatro da Vertigem (mas também peças como Inferno da Socìetas Raffaello Sanzio) se apropriam dos espaços promovendo uma ressignificação simbólica a partir das lembranças de cada espectador. É possível imaginar o sentimento de uma pessoa que ficou presa durante algum tempo na prisão em Belo Horizonte e que volta para seu antigo cárcere assistir uma peça de teatro. As experiências relatadas são tão múltiplas e complexas, que parece natural que continuem a se desenvolver após o fim da sessão do espetáculo. Muitas vezes a experiência somente atinge um fim ao ser relatada, verbalmente ou de forma escrita, tal como descreve Alessandra Montagner (2013, p.37-38) ao falar de sua experiência como espectadora de Sobre o conceito da face do filho de Deus (Socìetas Raffaello Sanzio).

Há mais de dois anos eu me propus a fazer o que aqui refaço. Lancei-me a escrever sobre a intangibilidade e extrema significância de uma experiência, buscando apreender aspectos daquela vivência que me afetaram profundamente no meu comparecimento a uma representação teatral. Retorno à mesma tarefa, pois as marcas daquele evento continuam a viver em mim como uma experiência que me intriga até os dias de hoje, quando por algum motivo curioso ainda me pergunto: que experiência foi aquela, como o teatro se fez tão contraditório em mim? Naquela ocasião eu era parte de uma congregação de indivíduos que conjuntamente lotava o auditório do Barbican Theatre em Londres. Enquanto eu adentrava aquele espaço, comigo vinham uma apreensão nervosa e uma curiosidade ansiosa, pois eu havia esperado inquietamente por aquele momento: presenciar e vivenciar o trabalho, o afeto e o efeito do teatro produzido pelo grupo Societas Raffaello Sanzio. Porém, penso que a intensidade de tal expectativa contribuiu para um desfecho frustrante: ao final da representação eu fui expelida do teatro, pelo próprio teatro, com um sentimento contraditório composto de ambos prazer e desconforto. Creio que o prazer que me inundava resultava do domínio hábil 
do palco e de seus recursos, era o prazer estético adquirido pela apreciação de uma brilhante articulação da cena e seus meios. Por outro lado, confio que a sensação de desconforto, que comigo deixou o auditório, derivou da percepção de que algo a respeito daquela encenação, daquela experiência, parecia estar errado, equivocado, incompleto. Havia naquele trabalho, e em mim, após presenciar este, uma grande falha, um enorme vão, algo que não possuía nome, mas que era definitivamente angustiante. Ao término do evento, eu me encontrava perturbada e estava literalmente transformada! Assim, ambiciosamente, busco retomar nesse texto a intensidade daquilo que atuou sobre mim, e cobiço, nessa performatividade, o apontamento de uma presença ausente que me acompanha neste (exato e pretendido) evento textual.

Ainda que a memória consciente (ou explicita) da espectadora seja capaz de sintetizar a experiência do espetáculo, a grande quantidade e intensidade de estímulos a sua atenção parece ter deixado outros elementos em sua memória implícita. Tais elementos permanecem gravados na sua memória e são, por vezes, retomados como lembranças de uma fruição traumática. Mesmo que haja o prazer, há também um processo de trauma pelo rompimento da barreira atencional (CARNEIRO, 2011), que merece ser estudado mais a fundo.

Nesse contexto, parece apropriado dizer que ocorre uma recepção traumática do espectador, como aponta Laura. É na vertigem do espectador, causada pelos choques sucessivos em sua percepção, que o evento teatral se instala e se desenvolve nas camadas mais subterrâneas da memória, pronto para emergir a qualquer momento na experiência da vida comum.

\section{Referências bibliográficas}

ARDENNE, Paul. Extrême: Esthétiques de la limite dépassée. Paris: Flammarion, 2006. ARISTÓTELES. Metafísica, Ética à Nicômaco, Poética. Coleção os Pensadores. São Paulo: Ed. Abril Cultural, 1984.

BENJAMIN, Walter. Magia e técnica, arte e política: ensaios sobre literatura e história da cultura - V1. São Paulo: Brasiliense, 1985.

BONDÍA, Jorge Larrosa. Notas sobre a experiência e o saber de experiência. In: Revista Brasileira de Educação, Rio de Janeiro, ANPED, Jan/Fev/Mar/Abr/2002, v.19 p. 20-29, 2002. BOURRIAUD, Nicolas. Estética relacional. São Paulo: Martins, 2009.

CARNEIRO, Leonel Martins. A atenção e a cena. 2011. Dissertação (Mestrado em Teoria e Prática do Teatro) - Escola de Comunicações e Artes, Universidade de São Paulo, São Paulo, 2011. Disponível em: <http://www.teses.usp.br/teses/disponiveis/27/27156/tde-16122011000016/>. Acesso em: 09-09-2013.

DARWIN, Charles. A Expressão das emoções no homem e nos animais. Tradução de Leon S. L. Garcia. São Paulo: Companhia das Letras, 2000.

DEWEY, John. Arte como experiência. São Paulo: Martins Fontes, 2010.

Art as experience. New York: Perigee Books, 2005. 
The early works, 1882-1898.Carbondale: Southern Illinois University Press, 1969.

The middle works, 1899-1924. Carbondale: Southern Illinois University Press, 2008.

FÉRAL, Josette. O real na arte: a estética do choque In: RAMOS, L. F. (Org.). Arte e Ciência: abismo de rosas. Porto Alegre: Abrace, 2012.

Théorie et pratique du theater: Au-delà des limites. Paris: L'Entretemps, 2011.

FERNANDES (S. TELESI), Sílvia. Teatralidades contemporâneas. São Paulo: Perspectiva, 2010.

(Org.). Teatro da Vertigem- BR-3. São Paulo: Perspectiva, 2006.

. Teatralidades do real. Subtexto, Belo Horizonte, v. 6, p. 37-48, 2009.

FISCHER-LICHTE, Érika. The transformative power of performance. London, Routledge, 2008.

KONDER, L. Walter Benjamin. O marxismo da melancolia. Rio de Janeiro: Civilização Brasileira, 1999.

LUCRÉCIO (Tito Lucrécio Caro. Da Natureza In: Epicuro, Lucrécio, Cícero, Sêneca, Marco Aurélio - Coleção os Pensadores. 2ª Ed. São Paulo, Ed. Abril, 1980.

MERVANT-ROUX, Marie-Madeleine. L'assise du théâtre: Pour une étude du spectateur. Paris: CRNS, 1998.

Figurations du spectateur: Une réflexion par l'image sur le théâtre et sur sa théorie. Paris: Harmattan,2006.

MONTAGNER, Alessandra. Sobre o Conceito do Rosto do Filho de Deus: A Inexplicabilidade de Uma Perda Sem Nome. Revista aSPAs, [S.I.], v. 3, n. 1, p. 37-48, dez. 2013. ISSN 22383999. Disponível em: <http://revistas.usp.br/aspas/article/view/68384/70925>. Acesso em: 03 Dez. 2013. DOI: 10.11606/issn.2238-3999.v3i1p37-48.

MÜNSTERBERG, Hugo. The Film: A Psychological Study. New York: Dover Publications, 2004.

PLATÃO. A República [ou sobre a justiça, diálogo político] - Tradução Anna Lia Amaral de Almeida Prado. São Paulo: Martins Fontes, 2006.

SAISON, Maryvonne. Les théâtres du réel. Paris: L'Harmattam, 1998.

SÁNCHEZ, José Antonio. Prácticas de lo real em la escena contemporânea. Madrid: Visor Libros, 2007.

TURNER, Victor. Dramas, campos e metáforas. Ação simbólica na sociedade humana. Niterói, RJ: Eduff, 2008.

The anthropology of performance. New York: PAJ Publications, 1988

VIGOTSKI, Lev Semionovitch. A formação social da mente. São Paulo: Martins Fontes, 1991.

A construção do pensamento e da linguagem. São Paulo: WMF Martins Fontes, 2010.

\section{Obras teatrais}

Teatro da Vertigem

BOM RETIRO 958m. Direção geral: Antônio Araújo. Dramaturgia Joca Reiners Terron. Atores: Bia Bouissou; Conrado Caputto; Elton Santos; Ícaro Rodrigues; João Attuy; Kátia Bissoli; 
Luciana Schwinden; Mawusi Tulani; Naia Soares; Raquel Morales; Renato Caetano; Roberto Audio; Samuel Vieira; Sofia Boito. Desenho de luz: Guilherme Bonfanti. Direção de Arte: Amanda Antunes e Carlos Teixeira. Desenho de Som: Kako Guirardo. Trilha Sonora: Erico Theobaldo e Miguel Caldas. Figurinos: Marcelo Sommer. Dramaturgismo: Antonio Duran. São Paulo: Teatro da Vertigem, 2012

BR3. Direção geral: Antônio Araújo. Dramaturgia: Bernardo Carvalho. Atores: Bruna Lessa; Bruno Batista; Cácia Goulart; Daniela Carmona; Denise de Almeida; Ivan Kraut; Luciana Schwinden; Marília De Santis; Roberto Audio; Rodolfo Arantes; Sérgio Siviero; Sérgio Pardal; Vanderlei Bernardino; Telma Vieira. Assistente de Direção: Eliana Monteiro. Desenho de luz: Guilherme Bonfanti. Direção de Arte e Cenário: Márcio Medina. Figurinos e Adereços: Marina Reis. Criação e Direção Musical: Thiago Cury e Marcus Siqueira. Desenho de som: Kako Guirado. Coordenação Teórica e Dramaturgismo: Sílvia Fernandes e Ivan Delmanto. São Paulo: Teatro da Vertigem, 2006.

APOCALIPSE 11,1. Direção geral: Antônio Araújo. Dramaturgia: Dramaturgia: Fernando Bonassi. Atores: Joelson Medeiros; Luciana Schwinden; Luis Miranda; Mariana Lima; Mihlen Cortaz; Mika Winiavier; Miriam Rinaldi; Roberto Audio; Sergio Siviero; Vanderlei Bernardino. Direção de arte: Marcos Pedroso. Direção musical e trilha sonora: Laércio Resende. Assistente de direção: Marcos Bulhões (2000)/Eliana Monteiro (2002). Figurinos: Fábio Namatame. Desenho de luz: Guilherme Bonfanti. Desenho de som: Kako Guirado. São Paulo: Teatro da Vertigem, 2000.

O LIVRO DE Jó. Direção geral: Antônio Araújo. Dramaturgia: Luís Alberto de Abreu. Atores: Daniella Nefussi; Joelson Medeiros; Lismara Oliveira; Luciana Schwinden; Marcos Lobo; Mariana Lima; Marília de Santis; Matheus Nachtergaele; Miriam Rinaldi; Roberto Audio; Sergio Siviero; Siomara Schröder; Suia Legaspe; Vanderlei Bernardino. Músicos Alexandre Galdino/José Eduardo Areias; Camila Lordy; Flávia Maria; Giovanna Sanches; Miriam Cápua. Composição e direção musical: Laércio Resende. Figurinos e visagismo: Fábio Namatame. Desenho de luz: Guilherme Bonfanti. Direção de arte: Marcos Pedroso. Desenho de som: Kako Guirado. Coordenação teórica: Ivan Marques. Assistente de direção: Marcos Lobo. Direção de cena: Eliana Monteiro. São Paulo: Teatro da Vertigem, 1995.

O PARAíso PERDIDo. Direção geral: Antônio Araújo. Dramaturgia: Sérgio de Carvalho. Atores: Cristina Lozano; Daniella Nefussi; Eliana César; Evandro Amorim; Johana Albuquerque; Luciana Schwinden; Lucienne Guedes; Luís Miranda; Marcos Lobo; Marta Franco; Matheus Nachtergaele; Mika Winiavier; Miriam Rinaldi; Ricardo lazetta; Roberto Audio; Sérgio Mastropasqua; Sérgio Siviero; Vanderlei Bernardino. Músicos: Alexandre Galdino; Atílio Marsiglia; Camila Lordy; Eduardo Areias; Fabiana Lian; Flávia Maria; Giovanna Sanches; Isaías Cruz; Laércio Resende; Magda Pucci; Marcos A. Boaventura; Marta Franco; Miguel Barella; Paulo Scharlack; Rita Carvalho; Roseli Câmara; Cláudio Gutierrez. Assistente de Direção: Eliana Monteiro. Composição e direção musical: Laércio Resende. Figurinos, adereços e visagismo: Fábio Namatame. Desenho de luz: Guilherme Bonfanti. São Paulo: Teatro da Vertigem, 1992.

\section{Societas Raffaello Sanzio}

\section{Ciclo "Il velo nero del pastore":}

THE FOUR SEASONS RESTAURANT. Direção: Romeo Castellucci. Música: Scott Gibbons. Atores: Chiara Causa, Silvia Costa, Laura Dondoli, Irene Petris. Cesena: Societas Raffaello Sanzio, 2012.

IL VELO NERO DEL PASTORE. Direção: Romeo Castellucci. Música: Scott Gibbons. Cesena: Societas Raffaello Sanzio, 2011. 
SUL CONCETTO DI VOLTO NEL FIGLIO DI DIO. Direção: Romeo Castellucci. Música: Scott Gibbons. Atores: Gianni Plazzi, Sergio Scarlatella, Dario Boldrini, Vito Matera, Silvano Voltolina.

Cesena: Societas Raffaello Sanzio, 2010.

Ciclo “La Divina Commedia”: Romeo Castellucci. Musica: Scott Gibbons.. Cesena: Socìetas Raffaello Sanzio, 2008

INFERNO

PURGATORIO

PARADISO

HEY GIRL!. Direção: Romeo Castellucci. Cesena: Socìetas Raffaello Sanzio, 2006

Ciclo "Tragedia Endogonidia": Direção: Romeo Castellucci. Música: Scott Gibbons.Cesena: Societas Raffaello Sanzio, 2002- 2004.

C.\#01 CESENA. I Episodio della Tragedia Endogonidia (2002)

A.\#02 AVIGNON. II Episodio della Tragedia Endogonidia (2002)

B.\#03 BERLIN. III Episodio della Tragedia Endogonidia (2003)

BR.\#04 BR.\#04 BRUXELLES/BRUSSEL. IV Episodio della Tragedia Endogonidia (2003)

BN.\#05 BERGEN. V Episodio della Tragedia Endogonidia (2003)

P.\#06 PARIS. VI Episodio della Tragedia Endogonidia (2003)

R.\#07 ROMA. VII Episodio della Tragedia Endogonidia (2003)

S.\#08 STRASBOURG. VIII Episodio della Tragedia Endogonidia (2004)

L.\#09 LONDON. IX Episodio della Tragedia Endogonidia (2004)

M.\#10 MARSEILLE. X Episodio della Tragedia Endogonidia (2004)

C.\#11 CESENA. XI Episodio della Tragedia Endogonidia (2004) 